\title{
Les endozépines, facteurs locaux de régulation de la stéroïdogenèse testiculaire
}

\author{
Céline DUPARC ${ }^{1}$, Hervé LEFEBVRE ${ }^{1,2}$, Marie-Christine TONON¹, Hubert VAUDRY1, \\ Jean Marc KUHN1,2
}

1IFRMP23, Laboratoire de Neuroendocrinologie Cellulaire et Moléculaire, INSERM U-413, Université de Rouen, Mont Saint Aignan, 2 Service d'Endocrinologie et Maladies Métaboliques, $\mathrm{CHU}$ de Rouen

\section{RESUME}

Les fonctions testiculaires endocrines et exocrines sont soumises à un contrôle multifactoriel complexe, impliquant les gonadotrophines circulantes et des signaux produits in situ responsables de régulations locales. Parmi ces facteurs locaux, les endozépines (EZ), ligands endogènes des récepteurs des benzodiazépines (BZD), semblent exercer un effet stimulant de type intracrine, autocrine et/ou paracrine sur la sécrétion leydigienne. Les effets des BZD sont relayés par deux types de récepteurs, le récepteur des BZD de type central (CBR) associé au complexe-récepteur GABAA-canal chlore, et le récepteur de type périphérique (PBR) principalement localisé sur la membrane mitochondriale et très abondant dans les cellules stéroïdogènes. La recherche de ligands endogènes pour ces récepteurs a permis l'identification d'une nouvelle famille de peptides, les EZ.

Toutes les EZ identifiées à ce jour dérivent d'un même précurseur, le diazepam-binding inhibitor (DBI) dont le clivage protéolytique conduit à différents peptides biologiquement actifs tels que le triakontatétraneuropeptide DBl17-50 (TTN) ou l'octadécaneuropeptide $\mathrm{DBI}_{33-50}$ (ODN). Les EZ sont très largement distribuées dans le cerveau et dans la plupart des organes périphériques en particulier les glandes stéroïdogènes, i.e. surrénale, testicule...

Différents travaux réalisés chez le rat suggèrent l'existence d'une implication des EZ dans le contrôle de la stéroïdogenèse testiculaire. Ainsi, l'expression du gène du DBI et la présence de peptides apparentés au DBI dans les cellules de Serto- li, de Leydig et dans certaines cellules germinales ont été démontrées. En outre, les EZ sont capables de stimuler la libération de progestérone et de testostérone par des cellules de Leydig de rat en culture et par des cellules de Leydig des lignées tumorales MA-10 ou R2C. Enfin, des études pharmacologiques ont montré que les effets des EZ sur la stéroïdogenèse testiculaire du rat s'exercent via l'activation d'un PBR. Le PBR serait alors le dernier maillon d'une chaîne d'interactions protéiques permettant la transduction des signaux de stimulation de la stéroïdogenèse, aboutissant à la translocation du cholestérol vers la membrane mitochondriale interne, où il est converti en prégnénolone, grâce à l'action enzymatique du cytochrome P450scc.

Mots Clés : endozépines, récepteurs des benzodiazépines, stéroïdogenèse testiculaire

Correspondance :

Dr Céline Duparc - Service d'Endocrinologie et Maladies Métaboliques, INSERM U-413, IFRMP 23, CHU de Rouen, Hôpital de Bois Guillaume, 1 rue de Germont 76031 ROUEN Cedex. France -

$\mathrm{Tel}$ 02.32.88.90.82 - Fax 02.32.88.91.54 -

Email CelDuparc@yahoo.fr 


\section{INTRODUCTION}

Le testicule adulte a deux fonctions majeures et complémentaires : la génération des gamètes (fonction exocrine) et la sécrétion de stéroïdes sexuels (fonction endocrine). Ces fonctions endocrine et exocrine sont soumises à un contrôle multifactoriel complexe impliquant notamment les gonadotrophines d'origine hypophysaire, LH et FSH, mais également de nombreux facteurs produits localement susceptibles de participer aux régulations autocrine, paracrine et/ou intracrine [125]. De nombreuses données obtenues à partir de modèles animaux suggèrent que les EZ, ligands endogènes des récepteurs des benzodiazépines (BZD), pourraient s'inscrire dans la liste des facteurs locaux capables de contrôler la stéroïdogenèse testiculaire.

En raison de leurs propriétés anxiolytiques, hypnotiques, myo-relaxantes, anticonvulsivantes et sédatives, les BZD constituent l'une des classes de médicaments les plus fréquemment prescrits dans les pays industrialisés [23]. Les principaux représentants de cette classe thérapeutique, dont le chef de file est le diazépam (Valium ${ }^{\circledR}$, Roche), sont répertoriés dans le Tableau 1. Ces différents composés possèdent des propriétés pharmacologiques distinctes notamment en raison d'affinités différentes pour les sites de liaison des BZD.

\section{SITES DE LIAISON DES BENZODIAZEPINES}

Bien que les BZD aient été commercialisées dés le début des années 1960, leurs sites de liaison n'ont été mis en évidence qu'à la fin des années 1970 [25, 91, 131]. Les études réalisées à l'aide du diazepam et du flunitrazepam tritiés ont permis d'identifier dans le cerveau des mammifères, des sites de liaison spécifiques, saturables et de haute affinité pour les BZD. La synthèse de nombreuses BZD a conduit à distinguer deux types de récepteurs désignés récepteurs centraux et périphériques. Les récepteurs de type central (CBR) sont essentiellement présents dans le cerveau $[29,91]$ et sont associés au complexe récepteurcanal chlore de l'acide $\gamma$-aminobutyrique de type A (R$\left.\mathrm{GABA}_{\mathrm{A}}\right)[39,40,59]$. Les récepteurs de type périphérique (PBR) sont exprimés à la fois dans le cerveau et dans la plupart des organes extra-cérébraux $[17,41,60]$.

\section{Récepteurs de type central (CBR)}

Le complexe récepteur $\mathrm{GABA}_{\mathrm{A}} /$ canal chlore/BZD est composé de 5 sous-unités formant un canal perméable aux ions chlorures, dont l'ouverture est contrôlée par le GABA [93] (Figure 1). Actuellement, 8 classes de sous-unités polypeptidiques $(\alpha, \beta, \gamma, \delta, \rho, \varepsilon, \pi$ et $\theta$ ) ont été identifiées et certaines présentent différentes isoformes $[24,64,110$, $122,123,128]$. Malgré la très grande diversité des combi- naisons théoriquement possibles à partir de ces sous-unités [65], les études électrophysiologiques, immunohistochimiques et biochimiques démontrent la prédominance d'un petit nombre d'associations correspondant à des stoechiométries de type $2 \alpha 2 \beta 1 \gamma[35,135]$ ou $2 \alpha 1 \beta 1 \gamma 1 \gamma / \delta[12,18$, 89]. Le site $\mathrm{GABA}_{\mathrm{A}}$ proprement dit est localisé à l'interface des sous-unités $\alpha$ et $\beta$ [128] alors que le site de liaison des BZD a initialement été localisé sur la sous-unité $\alpha$. Cependant, il a été depuis démontré que l'action des BZD sur le R-GABA $A_{A}$ nécessite en plus de la sous-unité $\alpha$, la présence d'une sous-unité $\gamma$ [27, 109]. Des expériences de mutagenèse dirigée suggèrent que les $B Z D$ se lient au sein d'une cavité située à la surface du récepteur $\mathrm{GABA}_{\mathrm{A}}$ et localisée à l'interface des sous unités $\alpha$ et $\gamma$ [44].

Il est clairement établi que les BZD, en interagissant avec le CBR, potentialisent les effets du GABA [36, 47, 48, 124]. Ainsi, les agonistes des $C B R$, tels que le diazépam et le clonazépam, ont un effet potentialisateur sur la transmission GABAergique [47] et possèdent de ce fait des propriétés anxiolytiques. Le seul antagoniste compétitif identifié à ce jour est le flumazénil (Ro15-1788) [51, 53, 66]. Celui-ci est utilisé en clinique pour contrecarrer les effets des BZD lors d'un surdosage volontaire ou accidentel.

La présence des CBR a été mise en évidence, par des techniques de liaison, d'immunohistochimie et d'hybridation in $s i t u$, dans de nombreuses régions du cerveau, en particulier dans le cortex [45], le striatum [138], le système limbique [99], la substance noire [94] et le cervelet [16]. Dans le système nerveux central (SNC), les CBR sont principalement exprimés dans les neurones mais également dans les cellules gliales $[33,136]$. La présence des CBR a également été mise en évidence dans l'hypophyse [21] et dans certains organes périphériques tels que les glandes salivaires [145] et la surrénale [108].

\section{Récepteurs de type périphérique (PBR)}

Les BZD se lient également à d'autres récepteurs localisés à la fois dans le cerveau au niveau des cellules gliales [84] mais surtout hors du SNC lesquels, de ce fait, sont désignés récepteurs des BZD de type périphérique (PBR) [29, $58,137]$. Ces récepteurs se distinguent pharmacologiquement des CBR car ils ne reconnaissent ni le clonazépam ni le flumazénil [74, 75, 119]. En revanche, ils présentent une affinité nanomolaire pour le 4'-chlorodiazépam (Ro54864) $[84,139]$. En outre, plusieurs molécules chimiquement différentes des BZD et spécifiques de ce récepteur ont été développées. Il s'agit de dérivés des isoquinolines carboxamides (PK11195, PK14105) [76, 77], des imidazopyridines telles que l'alpidem [8] et des indoleacétamides (FGIN-1-27) [69, 117].

Le PBR est un complexe hétéromérique formé d'au moins trois sous-unités protéiques différentes : une protéine de 


\begin{tabular}{|c|c|c|c|}
\hline $\mathrm{DCl}$ & Formule & $\begin{array}{l}\text { Indications } \\
\text { principales }\end{array}$ & Spécificité \\
\hline Diazépam & Valium ${ }^{\circledR}$ & Anxiolytique & $\begin{array}{l}\text { Ligand mixte } \\
\text { CBR/PBR }\end{array}$ \\
\hline Bromazépam & $\begin{array}{l}\text { Lexomil| } \\
\text { Anyrex® }\end{array}$ & Anxiolytique & \\
\hline chlordiazépoxide & $\begin{array}{l}\text { Librium }{ }^{8} ; \text { Librax® }\left(1^{\text {ere }} \text { co }\right. \\
1960)\end{array}$ & Anxiolytique & \\
\hline Nordazépam & Nordaz $®$ & Anxiolytique & \\
\hline Oxazépam & Séresta® & Anxiolytique & \\
\hline Chlorazépate & Tranxene® & Anxiolytique & \\
\hline Alprazolam & Xanax® & Anxiolytique & \\
\hline Lorazépam & Témesta ${ }^{\circledR}$ & Anxiolytique & \\
\hline Nitrazépam & Mogadon® & Hypnotique & \\
\hline Lormétazépam & Noctamide $®$ & Hypnotique & \\
\hline Flunitrazépam & $\begin{array}{l}\text { Rohypnol®, } \\
\text { Narcozep® }\end{array}$ & Hypnotique & $\begin{array}{l}\text { Agoniste } \\
\text { CBR/ } \\
\text { antagoniste } \\
\text { PBR }\end{array}$ \\
\hline Clonazépam & Rivotril@ & $\begin{array}{l}\text { Anticonvulsivant, } \\
\text { Antiépiléptique }\end{array}$ & $\begin{array}{l}\text { Agoniste } \\
\text { spécifique } \\
\text { des CBR }\end{array}$ \\
\hline Midazolam & Hypnovel@ & $\begin{array}{l}\text { Anesthésique, } \\
\text { hypnotique, } \\
\text { sédatif }\end{array}$ & \\
\hline $\begin{array}{c}\text { Flumazénil = } \\
\text { Ro 15-1788 }\end{array}$ & Anexate ${ }^{\circledR}$ & $\begin{array}{l}\text { Antidote }= \\
\text { Antagoniste des } \\
\text { benzodiazépines } \\
\text { lors } \\
\text { d'intoxications ou } \\
\text { d'anesthésies }\end{array}$ & $\begin{array}{l}\text { Antagoniste } \\
\text { spécifique du } \\
\text { CBR }\end{array}$ \\
\hline $\begin{array}{l}\text { 4'-chlorodiazépam = } \\
\text { Ro5-4864 }\end{array}$ & & $\begin{array}{l}\underline{\text { Effets }} \\
\underline{\text { compor }-} \\
\text { tementaux: } \\
\text { Propriétés } \\
\text { anxiogéniques et } \\
\text { convulsivantes }\end{array}$ & $\begin{array}{l}\text { Agoniste } \\
\text { spécifique du } \\
\text { PBR }\end{array}$ \\
\hline
\end{tabular}

DCI : dénomination commune internationale ; DC : dénomination commerciale. 


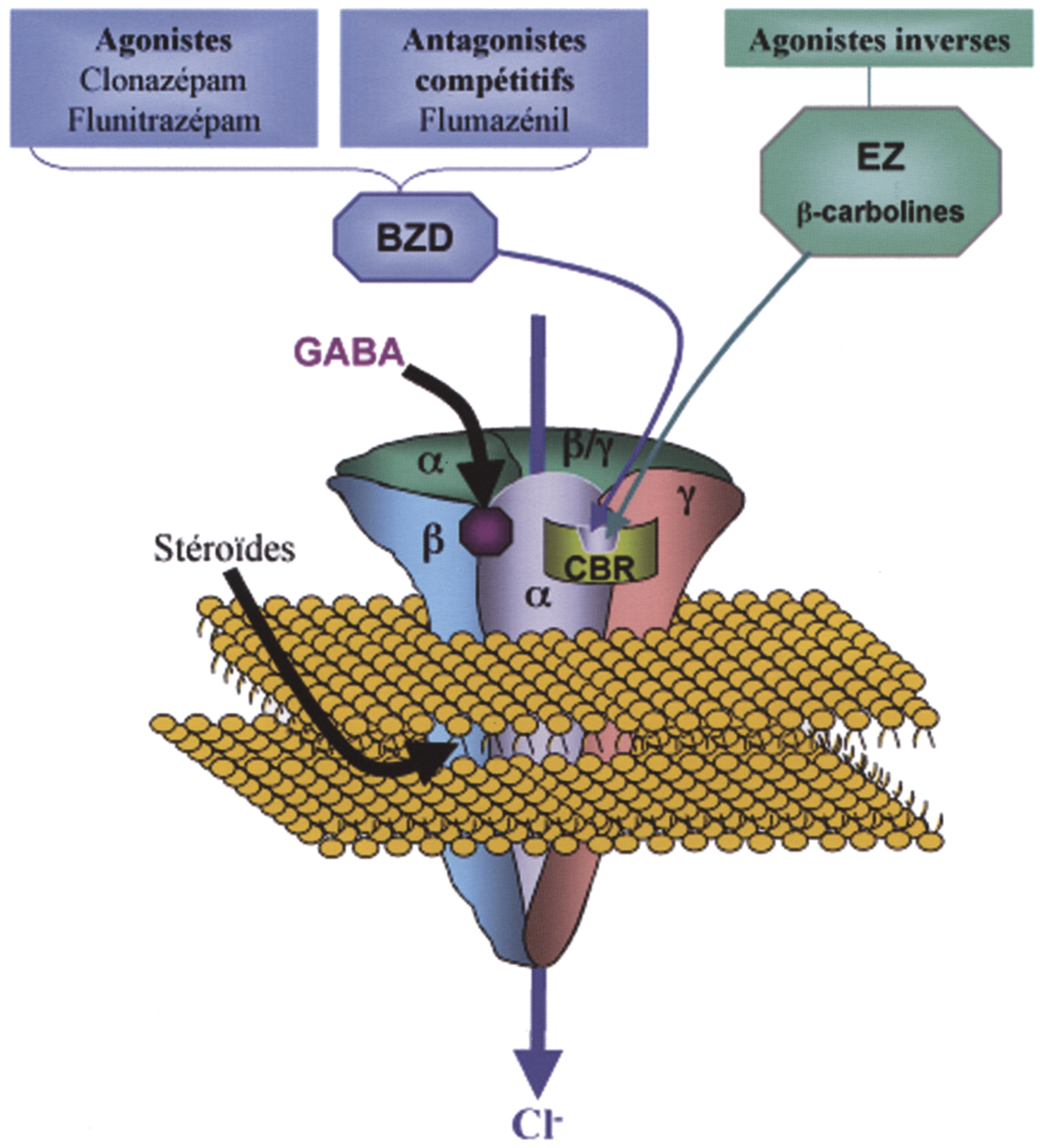

Figure 1 : Représentation schématique du CBR associé au complexe récepteur GABAA-canal chlore. Les agonistes CBR, qui agissent comme des modulateurs allostériques, potentialisent l'effet du GABA sur le courant chlore. Les endozépines (EZ) qui, à la façon des bcarbolines, agissent comme des agonistes inverses, inhibent l'effet du GABA sur le récepteur GABA . $^{\circ}$ 
liaison aux isoquinolines carboxamides, un canal anionique voltage-dépendant et un transporteur des nucléotides à adénine $[56,86,129]$.

Les premières tentatives de purification du PBR ont permis de caractériser la première de ces sous-unités, une protéine de $18 \mathrm{kDa}[7,114,130]$ qui possède une affinité nanomolaire pour les isoquinolines carboxamides et a de ce fait été dénommée isoquinoline-binding protein ou IBP [107]. L'ADNc de cette sous-unité a été cloné chez le rat [70, 130], l'homme [113], le bœuf [107] et la souris [56]. Il code une protéine de 169 acides aminés dont la structure primaire est bien conservée puisque l'on retrouve environ $80 \%$ d'identité dans les espèces mammifères étudiées. Le gène codant pour la protéine IBP est composé de 4 exons [83]. Chez l'homme, deux ARNm résultant d'un processus d'épissage alternatif ont été caractérisés : une forme longue et une forme très courte dépourvue de l'exon 2, incapable de coder la protéine du PBR. Cette forme courte est exprimée en quantités plus importantes que la forme longue chez les patients atteints d'hyperplasie surrénalienne lipoïde congénitale [57, 83].

A partir de la structure primaire de la protéine, un modèle tridimensionnel a été développé en utilisant des simulations moléculaires dynamiques. Ces études de modélisation ont révélé l'existence de 5 domaines transmembranaires, organisés en 5 hélices alpha, qui pourraient constituer un canal pour le cholestérol [100]. En outre, un site de reconnaissance/interaction pour le cholestérol a pu être caractérisé à l'extrémité C-terminale de la protéine [81].

Mc Enery et al. [86] ont montré que la protéine IBP est copurifiée avec deux autres protéines de masse respectives 32 et $30 \mathrm{kDa}$, lesquelles correspondent respectivement à un canal anionique voltage-dépendant (VDAC) de grand diamètre et de forte conductance, et à un transporteur des nucléotides à adénine (ANC). Alors que les isoquinolines carboxamides peuvent se lier à la protéine IBP seule, la liaison des BZD sur leurs sites spécifiques au niveau des sous-unités VDAC et ANC nécessite l'interaction des trois sous-unités [56, 100, 129]. Le PBR serait donc un complexe multiprotéique ternaire (IBP/VDAC/ANC) dans lequel, un groupe de 4 à 6 molécules d'IBP serait associé à la protéine VDAC favorisant ainsi la formation d'un pore [22, 100, 103] (Figure 2).

Chez les mammifères, les PBR sont présents dans les cellules gliales du SNC [84] et dans la majorité des organes périphériques [4]. Dans ces derniers, les PBR sont particulièrement abondants dans les glandes endocrines telles que la surrénale, le testicule, l'ovaire et le placenta $[41,49,88$, 137]. On trouve également des quantités importantes de PBR dans le rein, le cœur, l'utérus [137] ainsi que dans les érythrocytes et les plaquettes $[15,98]$. Des expériences de liaison réalisées à l'aide de ligands radioactifs spécifiques des PBR ont révélé une distribution différentielle de ces récepteurs dans divers organes. Chez le rat, les PBR ont ainsi été mis en évidence dans le cortex surrénalien [41], le tissu testiculaire interstitiel [55], le tubule contourné distal et la branche ascendante de l'anse de Henlé du rein [60]. Des études immunohistochimiques utilisant des anticorps dirigés contre la sous-unité protéique de $18 \mathrm{kDa}$ du PBR ont confirmé cette distribution différentielle [97].

Des expériences de liaison du PK11195, ligand spécifique des PBR, menées dans la surrénale, le testicule, le poumon, le rein, le cœur, le muscle squelettique, le foie et le cerveau du rat ont montré que les PBR sont localisés au niveau de la membrane mitochondriale $[5,6,14,95,96]$. Des études complémentaires réalisées dans la surrénale [5], le rein et le foie [95, 96] ainsi que dans la cellule de Leydig [103] ont permis de préciser la localisation des PBR sur la membrane mitochondriale externe. Cependant, la présence de PBR sur la membrane mitochondriale interne a également été rapportée dans le poumon du cobaye [92] ce qui suggère que ces récepteurs pourraient être localisés au niveau des sites de contact entre les membranes mitochondriales internes et externes [103].

L'existence de PBR au niveau de la membrane plasmique a également été décrite dans la surrénale de souris [97], dans le testicule de rat et dans la lignée tumorale à cellules de Leydig de souris MA-10 [55], ainsi que dans les cellules hématopoïétiques humaines [19, 34, 144].

La densité des PBR dans les différents tissus semble être sous contrôle hormonal. Ainsi, chez le rat, l'hypophysectomie provoque une réduction très importante des quantités de PBR dans la glande surrénale, le testicule et l'ovaire [3, 13, 50]. La déplétion en PBR est réversée par un traitement substitutif à l'ACTH et/ou aux gonadotrophines. La castration du rat mâle entraîne également une diminution importante des taux de PBR surrénaliens, effet qui est aboli par l'administration d'acétate de testostérone [2,141].

\section{LES ENDOZEPINES : LIGANDS ENDO- GENES DES RECEPTEURS DES BENZODIA- ZEPINES}

La mise en évidence de l'existence de sites de liaison spécifiques pour les benzodiazépines a tout naturellement conduit à rechercher les ligands endogènes de ces récepteurs. C'est ainsi qu'un polypeptide de $10 \mathrm{kDa}$, le diazepam-binding inhibitor (DBI) a pu être isolé à partir du cerveau de rat en raison de sa capacité à déplacer de façon compétitive la liaison des benzodiazépines à leurs récepteurs $[38,62]$. Le DBI est un peptide de 86 acides aminés dont la séquence est bien conservée d'une espèce à l'autre (Figure 3). Le DBI peut donner naissance par clivage pro-. téolytique à plusieurs peptides biologiquement actifs tels 


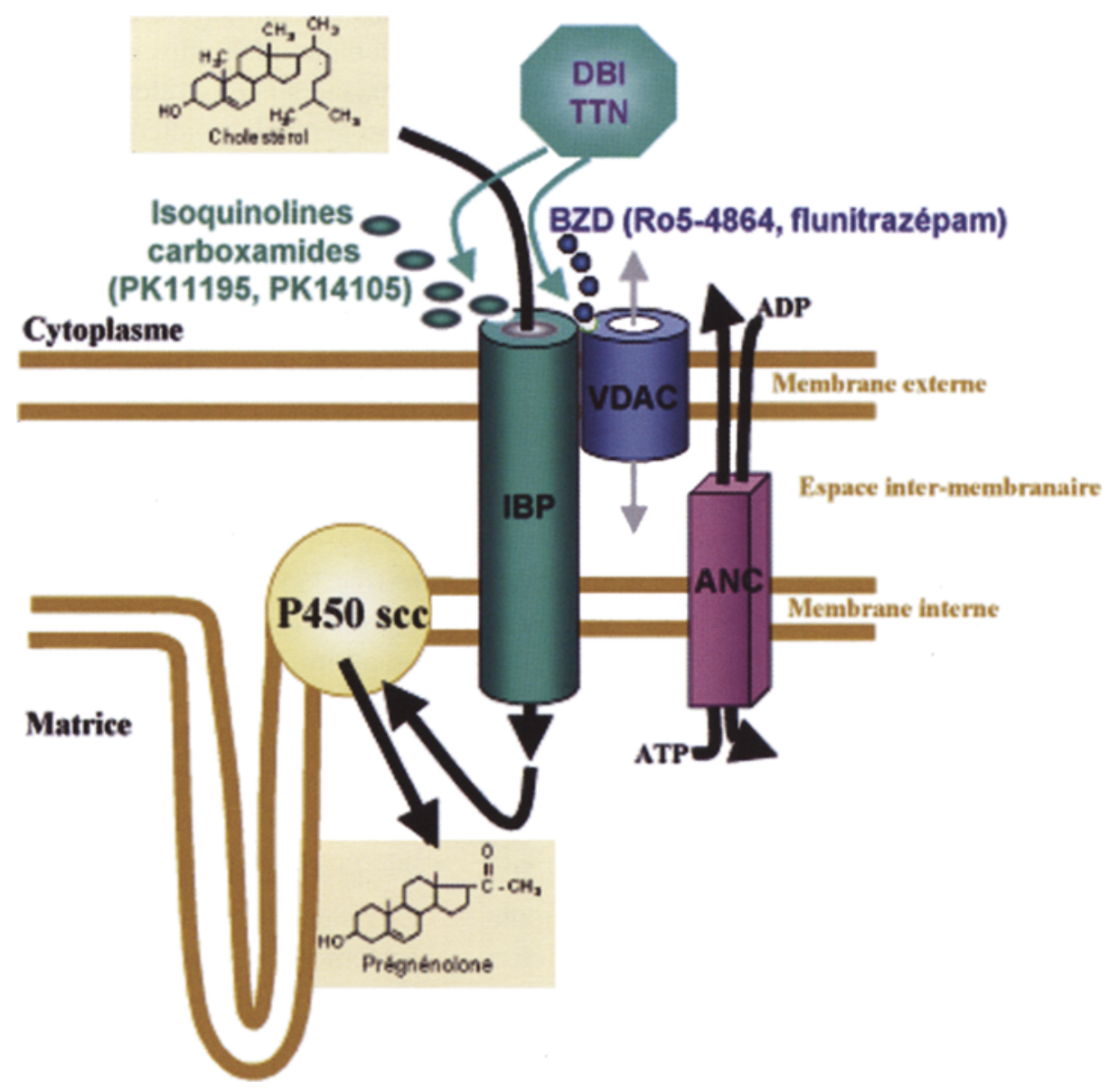

Figure 2 : Représentation schématique du PBR mitochondrial.

Les endozépines (DBI, TTN) en se liant sur le PBR entraînent des modifications de la conformation de ce récepteur et permettent ainsi le transfert du cholestérol vers l'intérieur de la mitochondrie via la sous unité IBP. Il en résulte une synthèse intramitochondriale de prégnénolone à partir du cholestérol. IBP, isoquinoline-binding protein; VDAC, voltage-dependent anionic channel; ANC, adenine nucleotide carrier.

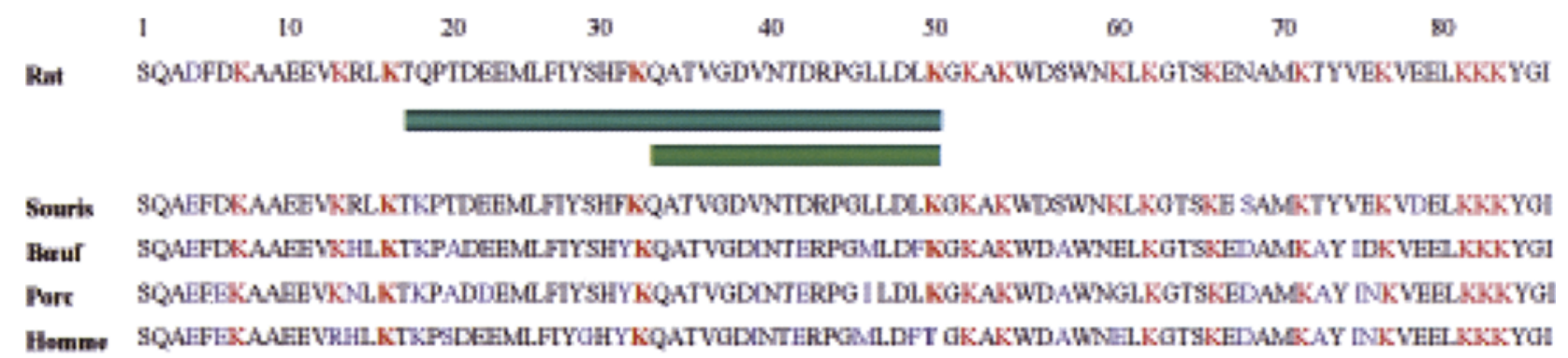

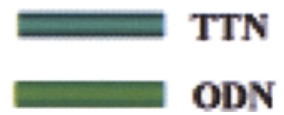

Figure 3 : Comparaison des séquences en acides aminés du diazepam-binding inhibitor (DBI) de rat, de souris, de bouf, de porc et humain. Les acides aminés figurés en bleu sont les acides aminés qui diffêrent par rapport à la séquence de rat. Les acides aminés basiques indiqués en rouge constituent des sites potentiels de clivage protéolytique, permettant notamment la formation du triakontatétraneuropeptide (TTN) et de l'octadécaneuropeptide (ODN). 
que le triakontaseptaneuropeptide $\mathrm{DBI}_{39-75}$, le triakontatétraneuropeptide $\mathrm{DBI}_{17-50}$ (TTN) et l'octadécaneuropeptide DBI33-50 (ODN) [51, 126, 127] (Figure 3). L'ODN présente une affinité élevée pour les CBR $[20,51,127]$ et module négativement la transmission GABAergique, alors que le TTN $[20,127]$ se lie préférentiellement aux PBR. Le DBI quant à lui est un ligand mixte pour les deux types de récepteurs [117].

Le gène du DBI est largement exprimé, tant au niveau du SNC que dans la plupart des organes périphériques [61]. Dans le cerveau des mammifères, le DBI est essentiellement présents dans les cellules gliales [133]. Le DBI et les peptides apparentés sont également très abondants dans les organes stéroïdogènes riches en PBR, tels que le cortex surrénalien, le testicule et l'ovaire $[1,28,68,78,112,118$, $133,134]$ ce qui suggère que les EZ pourraient être impliquées dans la régulation de la stéroïdogenèse. En accord avec cette hypothèse, les études menées sur différents modèles animaux de cellules stéroïdogènes - mitochondries isolées à partir de cellules de lignées tumorales corticosurrénaliennes (Y-1), leydigiennes (MA-10 ou R2C) [11], de cerveau ou de glioblastome de rat ; cellules de Leydig de rat ou corticosurénaliennes de grenouille en culture ; explants d'hypothalamus de grenouille - montrent que les EZ stimulent la biosynthèse des hormones stéroïdes et des neurostéroïdes [32, 42, 43, 54, 55, 79, 87, 102]. Certaines données obtenues in vivo semblent également confirmer cette hypothèse. Ainsi, chez le rat, il a été montré qu'un traitement par le diazepam entraîne une augmentation des taux plasmatiques de corticostérone [85] et de testostérone [37].

\section{IMPLICATION DES ENDOZEPINES DANS LE CONTRÔLE DE LA STEROIDO- GENESE TESTICULAIRE CHEZ LES MAMMIFERES}

Différentes données obtenues principalement chez le rat, suggèrent que les $E Z$ pourraient agir comme des facteurs locaux capables de réguler de façon autocrine, paracrine et/ou intracrine la biosynthèse des stéroïdes par les cellules de Leydig.

\section{Présence des EZ dans le testicule}

La présence d'ARNm du DBI dans les cellules de Leydig de rat a été mise en évidence par hybridation in situ [68, 112]. Ces données confirment les résultats antérieurs obtenus par analyse de Northern blot, montrant la présence de quantités importantes d'ARNm du DBI dans des homogénats testiculaires $[61,90,140]$. Une étude plus récente a également montré l'expression de l'ARNm du DBI dans les spermatides rondes des tubules séminifères et, à un moindre degré, dans les cellules de Sertoli chez le rat [68].
Parallèlement, la présence d'une immunoréactivité de type DBI a été observée par immunohistochimie dans le cytoplasme des cellules de Leydig $[28,55,68,112,120]$ ainsi que dans les cellules de Sertoli $[55,68,120]$. En outre, la mise en évidence de peptides apparentés au DBI dans le fluide interstitiel testiculaire ainsi que dans les milieux conditionnés à partir de cellules de Sertoli de rat en culture ou de cellules tumorales MA-10 confirme que ces deux types cellulaires secrètent des EZ et seraient donc à l'origine du DBI détecté dans le fluide interstitiel [55]. Une immunoréactivité de type DBI est également présente dans les cellules de la lignée germinale correspondant aux stades tardifs de la différenciation germinale, à savoir les spermatides allongées (stade VI) et les spermatozoïdes [68].

\section{Effets des EZ sur la stéroïdogenèse testiculaire}

Des travaux réalisés sur différents modèles animaux, ont permis de montrer que le DBI et les peptides dérivés stimulent la stéroïdogenèse testiculaire. Ainsi, le DBI purifié à partir du testicule de rat active le transport mitochondrial du cholestérol et stimule de façon dose-dépendante la formation de testostérone ou de prégnénolone par des cellules de Leydig de rat en culture ou des cellules de la lignée tumorale MA-10 [55]. Un effet stimulant du DBI et du TTN sur la biosynthèse de prégnénolone et de testostérone a également été observé lors d'expériences réalisées sur des mitochondries isolées à partir de ces cellules MA-10 $[55,102]$.

Par ailleurs, le DBI potentialise l'effet stimulant de faibles doses d'hCG sur la formation de progestérone et de testostérone par les cellules MA-10 et des cellules de Leydig de rat en culture, respectivement [55]. De plus, l'addition de DBI purifié ou recombinant à un système enzymatique de clivage de la chaîne latérale du cholestérol reconstitué in vitro stimule la conversion du cholestérol en prégnénolone [30]. Réciproquement, le traitement de cellules R2C (lignée tumorale de cellules de Leydig de rat produisant des stéroïdes de façon constitutive $[52,121]$ ) avec un oligonucleotide antisens pour le DBI, entraîne une inhibition de la production de progestérone [54], ce qui suggère que le DBI endogène exerce une stimulation tonique sur la stéroïdogenèse dans ces cellules. Dans ces mêmes cellules, le DBI induit une stimulation dose-dépendante de la production de progestérone par des mitochondries isolées [54]. De plus, il a été montré que la présence du DBI était indispensable à la stimulation aiguë de la stéroïdogenèse par les hormones trophiques. En effet, la déplétion en DBI dans des cellules de Leydig tumorales MA-10 provoque une inhibition de la production de stéroïdes induite par les gonadotrophines [26].

Ces données suggèrent donc que le DBI est important pour 
le maintien de la stéroïdogenèse constitutive et qu'il pourrait également être impliqué dans les mécanismes de régulation hormonale de la biosynthèse de prégnénolone [31, 104].

\section{Récepteurs impliqués dans le contrôle de la stéroï- dogenèse testiculaire par les endozépines}

Dans tous les tissus stéroïdogènes, la biosynthèse des stéroïdes débute par le clivage de la chaîne latérale du cholestérol pour former la prégnénolone. Cette réaction est catalysée par le cytochrome P450scc qui est localisé au niveau de la membrane mitochondriale interne. L'étape limitant la vitesse de ce processus est la translocation du cholestérol provenant des stocks intracytoplasmiques vers la membrane mitochondriale interne où est localisé le cytochrome P450scc.

De nombreuses données semblent indiquer que les PBR pourraient jouer un rôle majeur dans ce transport mitochondrial du cholestérol [71, 104]. Ainsi, le fait que les PBR soient principalement localisés au niveau de la membrane mitochondriale externe $[5,92,96]$ et leur abondance dans les tissus endocrines stéroïdogènes $[17,41]$ suggèrent un rôle des PBR dans la stéroïdogenèse. En outre, divers ligands des PBR (Ro5-4864, PK11195, PK14067) stimulent la biosynthèse des stéroïdes par les cellules de Leydig in vitro $[100,102,105,115]$. De même, une stimulation dose-dépendante de la biosynthèse de prégnénolone par les agonistes PBR a été observée sur des mitochondries intactes isolées à partir de cellules de Leydig, mais pas sur les mitoplastes (mitochondries dépourvues de membrane externe). Les PBR n'agissent donc pas par stimulation directe du P450scc [105] mais semblent plutôt augmenter la stéroïdogenèse en permettant l'activation du transport intramitochondrial du cholestérol [105, 115].

Parallèlement à leur effet sur la stéroïdogenèse spontanée, les PBR semblent impliqués dans la régulation hormonale de la biosynthèse des stéroïdes [106]. Ainsi, les ligands spécifiques des PBR, tels que le Ro5-4864, augmentent in vitro la sécrétion de testostérone stimulée par l'hCG dans le testicule de rat décapsulé et dans les cellules interstitielles en suspension $[115,116]$. En revanche, le flunitrazépam, qui se lie au PBR avec une affinité nanomolaire, inhibe de façon dose-dépendante la stéroïdogenèse constitutive dans les cellules de la lignée R2C [54] et la stéroïdogenèse stimulée par la LH/hCG ou l'AMPc dans les cellules de la lignée MA-10, via sa liaison au PBR [106]. Le flunitrazépam bloque également l'effet stimulateur du DBI sur la synthèse de stéroïdes $[102,106]$. De plus, il a été montré que le flunitrazepam inhibe la formation de prégnénolone dans des préparations de mitochondries isolées, en réduisant le transport du cholestérol vers la membrane mitochondriale interne.
Ces observations couplées à des études de déplacement de la liaison du flunitrazepam à l'aide de différents ligands des PBR confirment que l'action antagoniste du flunitrazepam sur la stéroïdogenèse stimulée par la $\mathrm{LH} / \mathrm{hCG}$ ou le DBI met en jeu les PBR et que la stéroïdogenèse hormonoinduite implique la participation des PBR [100, 104].

L'implication directe des PBR dans la stéroïdogenèse des cellules de Leydig a également été confirmée par des expériences de mutagénèse dirigée. Il a ainsi été montré dans deux lignées de cellules de Leydig tumorales (MA-10, $\mathrm{R} 2 \mathrm{C})$ que l'invalidation ciblée du gène de la sous-unité 18 $\mathrm{kDa}$ du PBR $[67,101]$ entraîne une diminution de la production des stéroïdes. En outre, dans les cellules n'exprimant pas le PBR, la production de stéroïdes peut être induite par l'ajout d'un dérivé hydrosoluble du cholestérol, le 22R-hydroxycholestérol, capable de traverser librement la membrane mitochondriale externe [101].

L'ensemble de ces données montre que les EZ produites par les cellules de Leydig, de Sertoli et certaines cellules germinales chez le rat sont potentiellement capables de réguler de façon intracrine et/ou autocrine/paracrine la stéroïdogenèse testiculaire via leur interaction avec les PBR.

\section{Hypothèses concernant le mécanisme d'action des EZ et des PBR dans le contrôle de la stéroïdoge- nèse}

Différentes observations semblent indiquer que le PBR pourrait être le maillon final d'une chaîne d'interactions protéines-protéines permettant la stimulation de la stéroïdogenèse par les hormones trophiques. Comme nous l'avons vu, le PBR possède une haute affinité pour le cholestérol $[73,82]$, et participe au transfert de ce dernier de la membrane mitochondriale externe vers la membrane mitochondriale interne. La translocation du cholestérol apparait comme un processus dynamique impliquant des interactions protéiques notamment entre le complexe PBR et la protéine StAR (steroidogenic acute regulatory protein) dont les niveaux d'expression sont, comme ceux du PBR, sous contrôle hormonal. Des travaux récents semblent indiquer que le PBR et la protéine StAR sont étroitement associés au niveau de la membrane mitochondriale externe et agissent de concert pour favoriser le transport du cholestérol à l'intérieur de la mitochondrie [132, 142]. Comme pour le PBR, la répression de StAR par l'utilisation d'un oligonucléotide antisens entraîne une inhibition de la stéroïdogenèse induite par l'hCG dans les cellules MA-10 [63]. La protéine StAR, au même titre que le PBR, joue donc un rôle essentiel dans la stimulation aiguë de la stéroïdogenèse induite par les hormones trophiques.

D'autres facteurs protéiques semblent également impliqués dans cette cascade de réactions, tels que la protéine PAP-7 (PBR-associated protein). Il a ainsi été montré que la pro- 
téine PAP-7 était capable d'interagir non seulement avec le PBR mitochondrial, mais aussi avec la sous-unité RIa cytosolique de la protéine kinase A (PKA) dans les cellules MA-10 [80]. L'utilisation d'un oligonucléotide antisens pour PAP-7 entraîne également une inhibition de la stéroïdogenèse stimulée par l'hCG montrant que cette protéine est l'un des éléments fonctionnels de la cascade de signalisation induite par les hormones et aboutissant à la synthèse des stéroïdes.

La présence de sites potentiels de phosphorylation par les protéines kinases au sein de PAP-7 suggère que la phosphorylation de la protéine pourrait faciliter son interaction avec le PBR (Figure 4). En outre, PAP-7 pourrait agir comme une protéine d'ancrage de la PKA, amenant celle-ci jusqu'à la mitochondrie où la phosphorylation de substrats protéiques spécifiques, tels que la protéine StAR, pourrait induire la réorganisation topographique et fonctionnelle du PBR [63]. En effet, il a été montré que la phosphorylation de StAR était responsable, au moins en partie, de la régulation de la stéroïdogenèse par les hormones [9].
Les quelques données de la littérature disponibles à ce jour $[63,80,111,142]$ semblent donc indiquer que la protéine StAR cytoplasmique pourrait jouer le rôle de transporteur du cholestérol permettant l'adressage de celui-ci à la membrane mitochondriale externe où il pourrait alors être transferé vers la membrane interne via le PBR.

Parallèlement, la protéine PAP-7 faciliterait l'interaction de la PKA avec différentes protéines cibles (StAR, sousunité de $18 \mathrm{kDa}$ du PBR [143], ...) modifiant ainsi l'organisation spatiale du PBR mitochondrial, ce qui aurait pour effet de favoriser la formation d'un canal transporteur du cholestérol [100]. Les EZ pourraient quant à elles modifier la conformation du PBR afin de permettre le transport du cholestérol et/ou faciliter les interactions PBR-StAR ou le transfert du cholestérol de StAR vers PBR (Figure 4).

Le transport du cholestérol, et par conséquent la formation des stéroïdes chez le rat, résulte donc d'un enchaînement complexe d'interactions protéines-protéines dont les acteurs principaux sont les EZ, les PBR et la protéine StAR.

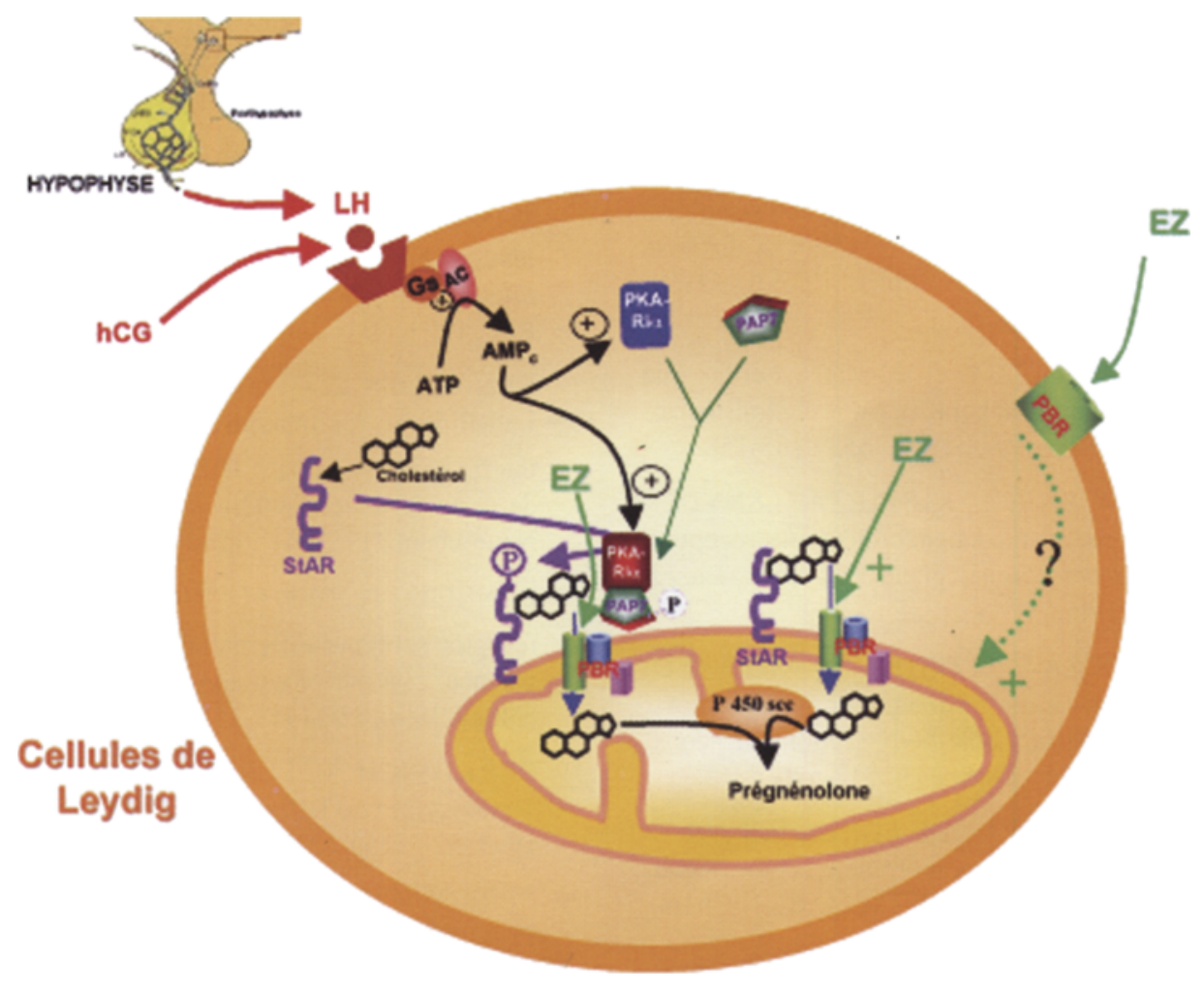

Figure 4 : Représentation schématique d'un modèle décrivant le mécanisme d'action des EZ dans la régulation de la stéroüdogenèse testiculaire basale et stimulée par l'hCG. La protéine StAR lie le cholestérol dans le cytoplasme et le transporte jusqu'à la mitochondrie où il est transféré vers le PBR. Le PBR, suite à son interaction avec différentes protéines (en particulier les EZ), subirait alors des modifications conformationnelles le rendant apte à transporter le cholestérol vers l'intérieur de la mitochondrie. La protéine PAP-7, en s'associant au $P B R$, favoriserait l'interaction des PKA avec d'autre protéines cibles, et modifierait ainsi la configuration et la fonction du PBR mitochondrial. Par ailleurs, le PBR serait également localisé au niveau de la membrane plasmique et un effet stimulateur des EZ a été observé sur des cellules intactes, suggérant que les EZ pourraient agir en tant que facteurs hormonaux ou paracrines pour contrôler la stéroüdogenèse testiculaire. 


\section{CONCLUSION}

L'ensemble de ces données montre donc que, chez le rat, les EZ produites dans le testicule s'inscrivent dans la liste des nombreux facteurs capables de réguler de façon intracrine, autocrine et/ou paracrine la stéroïdogenèse testiculaire, tant basale que stimulée par la LH/hCG. Ce contrôle endozépinergique de la stéroïdogenèse testiculaire du rat s'effectue via un PBR mitochondrial qui pourrait être le maillon final d'une châ̂ne complexe d'interactions protéines-protéines permettant la transduction des signaux de stimulation.

Chez l'homme, quelques rares données obtenues in vivo suggèrent que, comme chez le rat, les $\mathrm{EZ}$ pourraient moduler la stéroïdogenèse testiculaire. Il a ainsi été montré chez certains patients qu'un traitement par le diazepam ou l'oxazepam provoquait une augmentation des taux plasmatiques de testostérone [10, 46, 72]. Par ailleurs, des études réalisées in vitro dans notre laboratoire, indiquent que chez l'homme, il existe une production intratesticulaire d'EZ. En outre, ces EZ seraient capables de stimuler la production basale de testostérone par des fragments de tissu testiculaire humain en périfusion [Duparc et al., données non publiées].

\section{REFERENCES}

1. ALHO H., HARJUNTAUSTA T., SCHULTZ R., PELTO-HUIKKO M., BOVOLIN P. : Immunohistochemistry of diazepam binding inhibitor (DBI) in the central nervous system and peripheral organs: its possible role as an endogenous regulator of different types of benzodiazepine receptors. Neuropharmacology, 1991, $30: 1381-1386$.

2. AMIRI Z., WEIZMAN R., KATZ Y. et al. : Testosterone and cyproterone acetate modulate peripheral but not central benzodiazepine receptors in rats. Brain Res., 1991, $553: 155-158$.

3. ANHOLT R.R.H., DE SOUZA E.B., KUHAR M.J., SNYDER S.H. : Depletion of peripheral-type benzodiazepine receptors after hypophysectomy in rat adrenal gland and testis. Eur. J. Pharmacol., 1985, 110 : 41-46.

4. ANHOLT R.R.H., DE SOUZA E.B., OSTER-GRANITE M.L., SNYDER S.H. : Peripheral-type benzodiazepine receptors: Autoradiographic localization in whole-body sections of neonatal rats. J. Pharmacol. Exp. Ther., 1985, 233 : 517-526.

5. ANHOLT R.R.H., PEDERSON P.L., DE SOUZA E.B., SNYDER S.H. : The peripheral-type benzodiazepine receptor: localization to the mitochondrial outer membrane. J. Biol. Chem., 1986, $261: 576-583$.

6. ANTKIEWICZ-MICHALUK L., GUIDOTTI A., KRUEGER K.E. : Molecular characterization and mitochondrial density of a recognition site for peripheral-type benzodiazepine ligands. Mol. Pharmacol., 1988, 34 : 272-278.

7. ANTKIEWICZ-MICHALUK L., MUKHIN A.G., GUIDOTTI A., KRUEGER K.E. : Purification and characterization of a protein associated with peripheral-type benzodiazepine binding sites. J. Biol. Chem., 1988, 263 : 17317-17321.
8. ANZINI M., CAPPELLI A., VOMERO S. et al. : Molecular basis of peripheral vs central benzodiazepine receptor selectivity in a new class of peripheral benzodiazepine receptor ligands related to alpidem. J. Med. Chem., 1996, 39 : 4275-4284.

9. ARAKANE F., KING S.R., DU Y. et al. : Phosphorylation of steroidogenic acute regulatory protein (StAR) modulates its steroidogenic activity. J. Biol. Chem., 1997, 272 : 32656-32662.

10. ARGUELLES A.E., ROSNER J. : Diazepam and plasma testosterone levels. Lancet, 1975, $27: 607-608$.

11. ASCOLI M. : Characterization of several clonal lines of cultured Leydig tumor cells: gonadotropin receptors and steroidogenic responses. Endocrinology, 1981, 108 : 88-95.

12. BACKUS K.H., ARIGONI M., DRESCHER U. et al. : Stoichiometry of a recombinant $\mathrm{GABA}_{\mathrm{A}}$ receptor deduced from mutation-induced rectification. NeuroReport, 1993, 5 : 285-288.

13. BAR-AMI S., FARES F., GAVISH M. : Effect of hypophysectomy and hormone treatment on the induction of peripheral-type benzodiazepine binding sites in female rat genital axis. Horm. Metab. Res., 1989, $21: 106-107$.

14. BASILE A.S., SKOLNICK P. : Tissue specific regulation of «peripheral-type» benzodiazepine receptor density after chemical sympathectomy. Life Sci., 1988, 42 : 273-283.

15. BENAVIDES J., QUARTERONET D., PLOUIN P.F. et al. : Characterization of peripheral type benzodiazepine binding sites in human and rat platelets by using $\left[{ }^{3} \mathrm{H}\right] \mathrm{PK} 11195$. Studies in hypertensive patients. Biochem. Pharmacol., 1984, 33 : 24672472.

16. BENAVIDES J., PENY B., RUANO D., VITORICA J., SCATTON B. : Comparative autoradiographic distribution of central omega (benzodiazepine) modulatory site subtypes with high, intermediate and low affinity for zolpidem and alpidem. Brain Res., 1993, $604: 240-250$.

17. BENAVIDES J., QUARTERONET D., IMBAULT F. et al. : Labelling of «peripheral-type» benzodiazepine binding sites in the rat brain by using $\left[{ }^{3} \mathrm{H}\right] \mathrm{PK} 11195$, an isoquinoline carboxamide derivate: kinetic studies and autoradiographic localization. J. Neurochem., 1983, $41:$ 1744-1750.

18. BENKE D., HONER M., MICHEL C., MÖHLER H. : GABA A receptor subtypes differentiated by their $\gamma$-subunit variants: prevalence, pharmacology and subunit architecture. Neuropharmacology, 1996, 35 : 1413-1423.

19. BERKOVICH A., FERRARESE C., CAVALETTI G. et al. : Topology of two DBI receptors in human lymphocytes. Life Sci., $1993,52: 1265-1277$.

20. BERKOVICH A., MCPHIE P., CAMPAGNONE M., GUIDOTTI A., HENSLEY P. : A natural processing product of rat diazepam binding inhibitor, triakontatetraneuropeptide (diazepam binding inhibitor 17-50) contains an alpha-helix, which allows discrimination between benzodiazepine binding site subtypes Mol. Pharmacol., 1990, 37 : 164-172.

21. BERMAN J.A., ROBERTS J.L., PRITCHETT D.B. : Molecular and pharmacological characterization of $\mathrm{GABA}_{\mathrm{A}}$ receptors in the rat pituitary. J. Neurochem., 1994, 63 : 1948-1954.

22. BERNASSAU J.M., REVERSAT J.L., FERRARA P., CAPUT 
D., LE FUR G. : A 3D model of the peripheral benzodiazepine receptor and its implication in intra mitochondrial cholesterol transport. J. Molec. Graphics, 1993, $11: 236-245$.

23. BOIXET M., BATLE E., BOLIBAR I. : Benzodiazepines primary health care: a survey of general practitioners prescribing patterns. Addiction, 1996, 91 : 549-556.

24. BONNERT T.P., MCKERNAN R.M., FARRAR S. et al. : Theta, a novel gamma-aminobutyric acid type A subunit. Proc. Natl. Acad. Sci. USA, 1999, 96 : 9891-9896.

25. BOSMANN H.B., CASE K.R., DI STEFANO P. : Diazepam receptor characterization: specific binding of a benzodiazepine to macromolecules in various areas of rat brain. FEBS Lett., 1977, $82: 368-372$.

26. BOUJRAD N., HUDSON J.R., PAPADOPOULOS V. : Inhibition of hormone-stimulated steroidogenesis in cultured Leydig tumor cells by a cholesterol-linked phosphorothioate oligodeoxynucleotide antisense to diazepam binding inhibitor. Proc. Natl. Acad. Sci. USA, 1993, 90 : 5728-5731.

27. BOVOLIN P., SANTI M.R., PUIA G., COSTA E., GRAYSON D. : Expression patterns of $\gamma$-aminobutyric acide type A receptor subunit mRNAs in primary cultures of granule neurons and astrocytes from neonatal rat cerebella. Proc. Natl. Acad. Sci. USA, 1992, $89: 9344-9348$.

28. BOVOLIN P., SCHLICHTING J., MIYATA M., FERRARESE C., GUIDOTTI A., ALHO H. : Distribution and characterization of diazepam-binding inhibitor (DBI) in peripheral tissues of rat. Regul. Peptides, 1990, 29 : 267-281.

29. BRAESTRUP C., SQUIRES R. : Specific benzodiazepine receptors in rat brain characterized by high-affinity $\left[{ }^{3} \mathrm{H}\right]$ diazepam binding. Proc. Natl. Acad. Sci. USA, 1977, 74 : 3805-3809.

30. BROWN A.S., HALL P.F. : Stimulation by endozepine of the side-chain cleavage of cholesterol in a reconstituted enzyme system. Biochem. Biophys. Res. Commun., 1991, 180:609-614.

31. BROWN A.S., HALL P.F., SHOYAB M., PAPADOPOULOS V.: Endozepine/diazepam binding inhibitor in adrenocortical and Leydig cell lines : absence of hormonal regulation. Mol. Cell. Endocrinol., 1992, $83: 1-9$.

32. BROWN R.C., PAPADOPOULOS V. ; Role of the peripheraltype benzodiazepine receptor in adrenal and brain steroidogenesis. Int. Rev. Neurobiol., 2001, 46: 118-137.

33. BUREAU M., LASCHET J., BUREAU-HEEREN M. et al. : Astroglial cells express large amounts of $\mathrm{GABA}_{\mathrm{A}}$ receptor proteins in mature brain. J. Neurochem., 1995, $65: 2006-2015$.

34. CANAT X., CARAYON P., BOUABOULA M. et al. : Distribution profile and properties of peripheral-type benzodiazepine receptors on human hemopoietic cells. Life Sci., 1993, 52 : 107118.

35. CHANG Y., WANG R., BAROT S., WEISS D.S. : Stoichiometry of a recombinant $\mathrm{GABA}_{\mathrm{A}}$ receptor. J. Neurosci., 1996, 16 : $5415-5424$

36. CHERUBINI E., NORTH R.A. : Benzodiazepines both enhance g-aminobutyrate responses and decrease calcium action potentials in guinea-pig myenteric neurons. Neuroscience, 1985, 14 : 309-315.
37. COOK P.S., NOTELOVITZ M., KALRA P.S., KALRA S.P. : Effect of diazepam on serum testosterone and the ventral prostate gland in male rats. Arch. Androl., 1979, 3 : 31-35.

38. CORDA M.G., FERRARI M., GUIDOTTI A., KONKEL D., COSTA E. : Isolation, purification and partial sequence of a neuropeptide (diazepam binding inhibitor) precursor of an anxiogenic putative ligand for benzodiazepine recognition site. Neurosci. Lett., 1984, $47: 310-324$.

39. COSTA E., GUIDOTTI A. : Molecular mechanisms in the receptor action of benzodiazepines. Ann. Rev. Pharmac. Toxic., 1979, 19 : $531-545$.

40. DE LOREY T.M., OLSEN R.W. : Gamma-aminobutyric acid A receptor structure and function J. Biol. Chem., 1992, 267 : 16747-16750.

41. DE SOUZA E.B., ANHOLT R.R.H., MURPHY K.M.M., SNYDER S.H., KUHAR M.J. : Peripheral-type benzodiazepine receptors in endocrine organs: autoradiographic localization in rat pituitary, adrenal, and testis. Endocrinology, 1985, $116: 567$ 573

42. DO REGO J.L., MENSAH-NYAGAN A.G, BEAUJEAN D. et al. : The octadecaneuropeptide ODN stimulates neurosteroid biosynthesis through activation of central-type benzodiazepine receptors. J. Neurochem., 2001, $76: 128-138$.

43. DO REGO J.L., MENSAH-NYAGAN A.G., FEUILLOLEY M., FERRARA P., PELLETIER G., VAUDRY H. : The endozepine TTN stimulates neurosteroid biosynthesis in the frog hypothalamus. Neuroscience, 1998, $83: 555-570$.

44. DOBLE A. : New insights into the mechanism of action of hypnotics. J. Psychopharmacol,, 1999, 13 : S11-S20.

45. DUNCAN G.E., BREESE G.R., CRISWELL H.E. et al. : Distribution of $\left[{ }^{3} \mathrm{H}\right]$ zolpidem binding sites in relation to messenger RNA encoding the alpha 1 , beta 2 and gamma 2 subunits of $\mathrm{GABA}_{\mathrm{A}}$ receptors in rat brain. Neuroscience, 1995, $64: 1113-$ 1128 .

46. DUQUENNE M., ROHMER V., BREGEON C., MASSON C., BIGORGNE J.C. : Hypertestostéronémie après traitement par les benzodiazépines. Presse Med., 1997, 26 : 321.

47. EGHBALI M., CURMI J.P., BIRNIR B., GAGE P.W. : Hippocampal GABA(A) channel conductance increased by diazepam. Nature, 1997, $388: 71-75$.

48. FACKLAM M., SCHOCH P., HAEFELY W.E. : Relationship between benzodiazepine receptor occupancy and potentiation of gamma-aminobutyric acid-stimulated chloride flux in vitro of four ligands of differing intrinsic efficacies. J. Pharmacol. Exp. Ther., 1992, $261:$ 1106-1112.

49. FARES F., BAR-AMI S., BRANDES J.M., GAVISH M. : Gonadotropin- and estrogen-induced increase of peripheral-type benzodiazepine binding sites in the hypophyseal-genital axis of rats. Eur. J. Pharmacol., 1987, 133 : 97-102.

50. FARES F., BAR-AMI S., HAJ-YEHIA Y., GAVISH M. : Hormonal regulation of peripheral benzodiazepine binding sites in female rat adrenal gland and kidney. J. Recept. Res., 1989, 9 : 143-157.

51. FERRERO P., SANTI M.R., CONTI-TRONCONI B., COSTA E., GUIDOTTI A. : Study of an octadecaneuropeptide derived 
from diazepam binding inhibitor (DBI): biological activity and presence in rat brain. Proc. Natl. Acad. Sci. USA, 1986, 83 : 827831.

52. FREEMAN D.A. : Constitutive steroidogenesis in the R2C Leydig tumor cell line is maintained by the adenosine 3 ',5'-cyclic monophosphate-independent production of a cycloheximide-sensitive factor that enhances mitochondrial pregnenolone biosynthesis. Endocrinology, 1987, $120: 124-132$.

53 GALLAGER D.W., LAKOSKI J.M., GONSALVES S.F., RAUCH S.L. : Chronic benzodiazepine treatment decreases postsynaptic GABA sensitivity. Nature, 1984, 308 : 74-77.

54. GARNIER M., BOUJRAD N., OGWUEGBU S.O., HUDSON J.R., PAPADOPOULOS V. : The polypeptide diazepam-binding inhibitor and a higher affinity mitochondrial peripheral-type benzodiazepine receptor sustain constitutive steroidogenesis in the R2C Leydig tumor cell line. J. Biol. Chem., 1994, 269 : 2210522112.

55. GARNIER M., BOUJRAD N., OKE B.O., et al. : Diazepam binding inhibitor is a paracrine/autocrine regulator of Leydig cell proliferation and steroidogenesis: action via peripheral-type benzodiazepine receptor and independent mechanisms. Endocrinology, 1993, 132 : 444-458.

56. GARNIER M., DIMCHEV A.B., BOUJRAD N., PRICE J.M., MUSTO N.A., PAPADOPOULOS V. : In vitro reconstitution of a functional peripheral-type benzodiazepine receptor from mouse Leydig tumor cells. Mol. Pharmacol., 1994, 45 : 201-211.

57. GAVISH M., BACHMAN I., SHOUKRUN R. et al. : Enigma of the peripheral benzodiazepine receptor. Pharmacol. Rev., 1999, $51: 629-650$.

58. GAVISH M., BAR-AMI S., WEIZMAN R. : The endocrine system and mitochondrial benzodiazepine receptors. Mol. Cell. Endocrinol., 1992, $88: 1-13$.

59. GAVISH M., SNYDER S.H. : Gamma-aminobutyric acid and benzodiazepine receptors : copurification and characterization. Proc. Natl. Acad. Sci. USA, 1981, 78 : 1939-1942.

60. GEHLERT D.R., YAMAURA H.I., WAMSLEY J.K. : Autoradiographic localization of «peripheral» benzodiazepine binding sites in rat brain and kidney. Eur. J. Pharmacol., 1983, $95: 329$ 330 .

61. GRAY P.W., GLAISTER D., SEEBURG P.H., GUIDOTTI A., COSTA E. : Cloning and expression of cDNA for human diazepam binding inhibitor, a natural ligand of an allosteric regulatory site of the gamma-aminobutyric acid type A receptor. Proc. Natl. Acad. Sci. USA, 1986, 83 : 7547-7551.

62. GUIDOTTI A., FORCHETTI C.M., CORDA M.G., KONKEL D., BENNETT C.D., COSTA E. : Isolation, characterization and purification to homogeneity of an endogenous polypeptide with agonistic action on benzodiazepine receptors. Proc. Natl. Acad. Sci. USA, 1983, $80: 3531-3535$.

63. HAUET T., LIU J., LI H., GAZOULI M., CULTY M., PAPADOPOULOS V. : PBR, StAR, and PKA: partners in cholesterol transport in steroidogenic cells. Endocr. Res., 2002, 28 : 395401.

64. HEDBLOM E., KIRKNESS F. : A novel class of GABA receptor subunit in tissues of the reproductive system. J. Biol. Chem., 1997, $272: 15346-15350$.
65. HEVERS W., LUDDENS $\mathrm{H}$. : The diversity of $\mathrm{GABA}_{\mathrm{A}}$ receptors. Pharmacological and electrophysiological properties of GABA $_{A}$ channel subtypes. Mol. Neurobiol., 1998, 18 : 35-86.

66. HUNKELER W., MÖHLER H., PIERI L. et al. : Selective antagonists of benzodiazepines. Nature, 1981, $290: 514-516$.

67. KELLY-HERSHKOVITZ E., WEIZMAN R., SPANIER I. et al. : Effects of peripheral-type benzodiazepine receptor antisense knockout on MA-10 Leydig cell proliferation and steroidogenesis. J. Biol. Chem., 1998, 273 : 5478-5483.

68. KOLMER M., PELTO-HUIKKO M., PARVINEN M., HÖÖG C., ALHO H. : The transcriptional and translational control of diazepam binding inhibitor expression in rat male germ-line cells. DNA Cell. Biol., 1997, 16 : 59-72.

69. KOZIKOWSKI A.P., KOTOULA M., MA D., BOUJRAD N., TUCKMANTEL W., PAPADOPOULOS V. : Synthesis and biology of a 7-nitro-2,1,3-benzoxadiazol-4-yl derivative of 2-phenylindole-3-acetamide: a fluorescent probe for the peripheral-type benzodiazepine receptor. J. Med. Chem., 1997, 40 : 2435-2439.

70. KRUEGER K.E., MUKHIN A.G., ANTKIEWICZ-MICHALUK L., SANTI M.R., GRAYSON D.R., GUIDOTTI A. : Purification, cloning and expression of a peripheral-type benzodiazepine receptor. In : Biggio G. and Costa E. eds. GABA and Benzodiazepine Receptor Subtypes. New York, Raven Press, 1990, 1-13.

71. KRUEGER K.E., PAPADOPOULOS V. : Peripheral-type benzodiazepine receptors mediate translocation of cholesterol from outer to inner mitochondrial membranes in adrenocortical cells. J. Biol. Chem., 1990, 265 : 15015-15022.

72. KUHN J.M., LAUDAT M.H., WOLF L.M., LUTON J.P. : Hypertestostéronémie masculine. Presse Med., 1987, 16 : 675679.

73. LACAPERE J.J., DELAVOIE F., LI H. et al. : Structural and functional study of reconstituted peripheral benzodiazepine receptor (PBR). Biochem. Biophys. Res. Commun., 2001, 284 : 536 641 .

74. LANGER SZ, ARBILLA S. : Limitations of the benzodiazepine receptor nomenclature: a proposal for a pharmacological classification as omega receptor subtypes. Fundam. Clin. Pharmacol., $1988,2: 159-170$.

75. LANGER SZ, ARBILLA S., TAN S. et al. : Selectivity for omega-receptor subtypes as a strategy for the development of anxiolytic drugs. Pharmacopsychiatry, 1990, 23 : 103-107.

76. LE FUR G., GUILLOUX F., RUFAT P. et al. : Peripheral benzodiazepine binding sites: effect of PK11195, 1-(2-chlorophenyl)$\mathrm{N}$-methyl-(1-methylpropyl)-3 isoquinoline carboxamide. II. In vivo studies. Life Sci., 1983, 32 : 1849-1856.

77. LE FUR G., PERRIER M.L., VAUCHER N. et al : Peripheral benzodiazepine binding sites : effect of PK11195, 1-(2-chlorophenyl)-N-methyl-N-(1-methylpropyl)-3-isoquinolinecarboxamide. I. In vitro studies Life Sci., 1983, 32 : 1839-1847.

78. LESOUHAITIER O., FEUILLOLEY M., LIHRMANN I, et al. : Localization of diazepam-binding inhibitor-related peptides and peripheral type benzodiazepine receptors in the frog adrenal gland. Cell Tissue Res., 1996, 283 : 403-412.

79. LESOUHAITIER O., KODJO M.K., CARTIER F. et al. : The effect of the endozepine triakontatetraneuropeptide on corticoste- 
roid secretion by the frog adrenal gland is mediated by activation of adenylyl cyclase and calcium influx through T-type calcium channel. Endocrinology, 2000, 141 : 197-207.

80. LI H., DEGENHARDT B., TOBIN D., YAO Z.X., TASKEN K., PAPADOPOULOS V. : Identification, localization, and function in steroidogenesis of PAP7: a peripheral-type benzodiazepine receptor- and PKA (RIalpha)-associated protein. Mol. Endocrinol., 2001, $15: 2211-2228$.

81. LI H., PAPADOPOULOS V. : Peripheral-type benzodiazepine receptor function in cholesterol transport: identification of a putative cholesterol recognition/interaction amino acid sequence and consensus pattern. Endocrinology, 1998, $139: 4991-4997$.

82. LI H., YAO Z.X., DEGENHARDT B., TEPER G., PAPADOPOULOS V. : Cholesterol binding at the cholesterol recognition/interaction amino acid consensus (CRAC) of the peripheral-type benzodiazepine receptor and inhibition of steroidogenesis by HIV TAT-CRAC peptide. Proc. Natl. Acad. Sci. USA, 2001, $98: 1267-1272$.

83. LIN D., CHANG Y.J., STRAUSS J.F. III, MILLER W.L. : The human peripheral benzodiazepine receptor gene: cloning and characterization of alternative splicing in normal tissues and in a patient with congenital lipoid adrenal hyperplasia. Genomics, $1993,18: 643-650$.

84. MARANGOS P.J., PATEL J., BOULENGER J.P., CLARKROSENBERG R. : Characterization of peripheral-type benzodiazepine binding sites in brain using $\left[{ }^{3} \mathrm{H}\right] \mathrm{Ro5}-4864$. Mol. Pharmacol., 1982, $22: 26-32$.

85. MARC V., MORSELLI P.L. : Effect of diazepam on plasma corticosterone levels in the rat. J. Pharm. Pharmacol., 1969, 21 : 784-786.

86. Mc ENERY M.W. , SNOWMAN A.M., TRIFILETTI R.R., SNYDER S.H. : Isolation of the mitochondrial benzodiazepine receptor: association with the voltage-dependent anion channel and the adenine nucleotide carrier. Proc. Natl. Acad. Sci. USA, $1992,89: 3170-3174$

87. MCCAULEY L.D., PARK C.H., LAN N.C., TOMICH J.M., SHIVELY J.E., GEE K.W. : Benzodiazepines and peptides stimulate pregnenolone synthesis in brain mitochondria. Eur. J. Pharmacol., 1995, $276:$ 45-153.

88. MERCER K.A., WEIZMAN R., GAVISH M. : Ontogenesis of peripheral benzodiazepine receptors: demonstration of selective up-regulation in rat testis as a function of maturation. J. Recept. Res., 1992, $12: 413-425$.

89. MERTENS S., BENKE D., MÖHLER H. : GABA $_{A}$ receptor populations with novel subunit combinations and drug-binding profiles identified in brain by a5- and d-subunit-specific immunopurification. J. Biol. Chem., 1993, 268 : 5965-5973.

90. MOCCHETTI I., EINSTEIN R., BROSIUS J. : Putative diazepam binding inhibitor peptide : cDNA clones from rat. Proc. Natl. Acad. Sci. USA, 1986, 83 : 7221-7225.

91. MÖHLER H., OKADA T. : Benzodiazepine receptor : demonstration in the central nervous system. Science, 1977, $198: 849$ 851 .

92. MUKHERJEE S., DAS S.K. : Subcellular distribution of «peripheral-type» binding sites for $\left[{ }^{3} \mathrm{H}\right]-\mathrm{Ro5}-4864$ in guinea pig lung: Localization to the mitochondrial inner membrane. J. Biol. Chem., 1989, 264 : 16713-16718.

93. NAYEEM N., GREEN T.P., MARTIN L.L., BARNARD E.A. : Quaternary structure of the native $\mathrm{GABA}_{\mathrm{A}}$ receptor determined by electron microscopic image analysis. J. Neurochem., 1994, 62 : 815-818.

94. NICHOLSON L.F., FAULL R.L., WALDVOGEL H.J., DRAGUNOW M. : The regional, cellular and subcellular localization of $\mathrm{GABA}_{\mathrm{A}}$ /benzodiazepine receptors in the substantia nigra of the rat. Neuroscience, $1992,50: 355-370$.

95. O' BEIRNE G.B., WILLIAMS D.C. : The subcellular location in rat kidney of the peripheral benzodiazepine acceptor. Eur. J. Biochem., 1988, $175:$ 413-421.

96. O' BEIRNE G.B., WOODS M.J., WILLIAMS D.C. : Two subcellular locations for peripheral-type benzodiazepine acceptors in rat liver. Eur. J. Biochem., 1990, 188: 131-138.

97. OKE B.O., SUAREZ-QUIAN C.A., RIOND J., FERRARA P., PAPADOPOULOS V.: Cell surface localization of the peripheral-type benzodiazepine receptor (PBR) in adrenal cortex. Mol. Cell. Endocrinol., 1992, 87 : R1-R6.

98. OLSON J.M., CILIAX B.J., MANCINI W.R., YOUNG A.B. : Presence of peripheral-type benzodiazepine binding sites on human erythrocyte membranes. Eur. J. Pharmacol., 1988, 152 : 47-53.

99. ONOE H., TSUKADA H., NISHIYAMA S. et al. : A subclass of $\mathrm{GABA}_{\mathrm{A}}$ /benzodiazepine receptor exclusively localized in the limbic system. NeuroReport, 1996, 8 : 117-122.

100. PAPADOPOULOS V., AMRI H., BOUJRAD N. et al. : Peripheral benzodiazepine receptor in cholesterol transport and steroidogenesis. Steroids, 1997, $62: 21-28$.

101. PAPADOPOULOS V., AMRI H., LI H., BOUJRAD N., VIDIC B., GARNIER M. : Targeted disruption of the peripheral-type benzodiazepine receptor gene inhibits steroidogenesis in the R2C Leydig tumor cell line. J. Biol. Chem., 1997, 272 : 3212932135 .

102. PAPADOPOULOS V., BERKOVICH A., KRUEGER K.E., COSTA E., GUIDOTTI A. : Diazepam binding inhibitor and its processing products stimulate mitochondrial steroid biosynthesis via an interaction with mitochondrial benzodiazepine receptors. Endocrinology, 1991, $129: 1481-1488$.

103. PAPADOPOULOS V., BOUJRAD N., IKONOMOVIC M.D., FERRARA P., VIDIC B. : Topography of the Leydig cell mitochondrial peripheral-type benzodiazepine receptor. Mol. Cell. Endocrinol., 1994, 104 : R5-R9.

104. PAPADOPOULOS V., BROWN S. : Role of the peripheral-type benzodiazepine receptor and the polypeptide diazepam binding inhibitor in steroidogenesis. J. Steroid Biochem. Mol. Biol., 1995, $53: 103-110$.

105. PAPADOPOULOS V., MUKHIN A.G., COSTA E., KRUEGER K.E. : The peripheral-type benzodiazepine receptor is functionally linked to Leydig cell steroidogenesis. J. Biol. Chem., $1990,265: 3772-3779$.

106. PAPADOPOULOS V., NOWZARI F.B., KRUEGER K.E. : Hormone-stimulated steroidogenesis is coupled to mitochondrial benzodiazepine receptors. J. Biol. Chem., 1991, 266 : 
$3682-3687$.

107. PAROLA A.L., STUMP D.G., PEPPER D.J., KRUEGER K.E., REGAN J.W., LAIRD H.E. II : Cloning and expression of a pharmacologically unique bovine peripheral-type benzodiazepine receptor isoquinoline binding protein. J. Biol. Chem., 1991, $266: 14082-14087$.

108. PARRAMON M., OSET-GASQUE M.J., GONZALEZ M.P.,

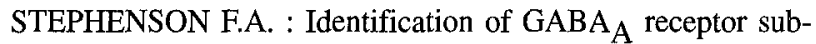
units expressed in bovine adrenal medulla. Neurosci. Lett., 1994, $168: 243-246$.

109. PRITCHETT D.B., SONTHEIMER H., SHIVERS B.D. et al. : Importance of a novel $\mathrm{GABA}_{\mathrm{A}}$ receptor subunit for benzodiazepine pharmacology. Nature, 1989, $338: 582-585$.

110. RABOW L.E., RUSSEK S.J., FARB D.H. : From ion currents to genomic analysis: recent advances in $\mathrm{GABA}_{\mathrm{A}}$ receptor research. Synapse, 1995, $21: 189-274$.

111. RAO R.M., JO Y., BABB-TARBOX M., SYAPIN P.J., STOCCO D.M. : Regulation of steroid hormone biosynthesis in R2C and MA-10 Leydig tumor cells: role of the cholesterol transfer proteins StAR and PBR. Endocr. Res., 2002, 28 : 387-394.

112. RHEAUME E., TONON M.C., SMIH F. et al. : Localization of the endogenous benzodiazepine ligand octadecaneuropeptide in the rat testis. Endocrinology, 1990, $127: 1986-1994$.

113. RIOND J., MATTEI M.G., KAGHAD M. et al. : Molecular cloning and chromosomal localization of a human peripheraltype benzodiazepine receptor. Eur. J. Biochem., 1991, 195 : 305-311.

114. RIOND J., VITA N., LE FUR G., FERRARA P. : Characterization of a peripheral-type benzodiazepine-binding site in the mitochondria of Chinese hamster ovary cells. FEBS Lett., 1989, $245: 238-244$.

115. RITTA M.N., CALANDRA R.S. : Testicular interstitial cells as targets for peripheral benzodiazepines. Neuroendocrinology, $1989,49: 262-266$.

116. RITTA M.N., CAMPOS M.B., CALANDRA R.S. : Effect of GABA and benzodiazepines on testicular androgen production. Life Sci., 1987, 40 : 791-798.

117. ROMEO E., AUTA J., KOZIKOWSKI A.P. et al. : 2-Aryl-3indoleacetamides (FGIN-1): a new class of potent and specific ligands for the mitochondrial DBI receptor (MDR). J. Pharmacol. Exp. Ther., 1992, 262 : 971-978.

118. ROUET-SMIH F., TONON M.C., PELLETIER G., VAUDRY $\mathrm{H}$. : Characterization of endozepine-related peptides in the central nervous system and peripheral tissues of the rat. Peptides, 1992, $13: 1219-1225$.

119. SCHOEMAKER H., BOLES R.G., HORST W.D., YAMAMURA H.I. : Specific high-affinity binding sites for $\left[{ }^{3} \mathrm{H}\right]$ Ro5-4864 in rat brain and kidney. J. Pharmacol. Exp. Ther., 1983, 225 : 61-69.

120. SCHULTZ R., PELTO-HUIKKO M., ALHO H. : Expression of diazepam binding inhibitor-like immunoreactivity in rat testis is dependent on pituitary hormones. Endocrinology, 1992, 130 : 3200-3206.

121. SHIN S.I., YASUMURA Y., SATO G.H. : Studies on interstitial cells in tissue culture. II. Steroid biosynthesis by a clonal line of rat testicular interstitial cells. Endocrinology, 1968, 82 : 614616.

122. SIEGHART W. : Structure and pharmacology of $\gamma$-aminobutyric acid A receptor subtypes. Pharmacol. Rev., 1995, 47 : 181224.

123. SIEGHART W., FUCHS K., TRETTER V. et al. : Structure and subunit composition of $\mathrm{GABA}(\mathrm{A})$ receptors. Neurochem. Int., $1999,34: 379-385$.

124. SIGEL E., BAUR R. : Allosteric modulation by benzodiazepine receptor ligands of the $\mathrm{GABA}_{\mathrm{A}}$ receptor channel expressed in Xenopus oocytes. J. Neurosci., 1988, 8 : 289-295.

125. SKINNER M.K. : Cell-Cell interactions in the testis. Endocr. Rev., 1991, $12:$ 45-77.

126. SLOBODYANSKY E., ANTKIEWICZ-MICHALUK L., MARTIN B. : Purification of a novel processing product, DBI 39-75 and characterization of its binding site in the rat brain. Regul. Peptides, 1994, 50 : 29-35.

127. SLOBODYANSKY E., GUIDOTTI A., WAMBEBE C., BERKOVITCH A., COSTA E. : Isolation and characterization of a rat brain triakontatetraneuropeptide (TTN) a posttranslational product of diazepam-binding inhibitor: specific action at the Ro5-4864 recognition site. J. Neurochem., 1989, 53 : 12761284.

128. SMITH G.B., OLSEN R.W. : Functional domains of GABA receptors. Trends Pharmacol. Sci., 1995, 16 : 162-168.

129. SNYDER S.H., MCENERY M.W., VERMA A. : Molecular mechanisms of peripheral benzodiazepine receptors. Neurochem. Res., 1990, 15: 119-123.

130. SPRENGEL R., WERNER P., SEEBURG P.H. et al. : Molecular cloning and expression of cDNA encoding a peripheral-type benzodiazepine receptor. J. Biol. Chem., 1989, 264 : 2041520421.

131. SQUIRES R., BRAESTRUP C. : Benzodiazepine receptors in rat brain. Nature, 1977, $266: 732-734$.

132. SRIDARAN R., PHILIP G.H., LI H. et al. : GnRH agonist treatment decreases progesterone synthesis, luteal peripheral benzodiazepine receptor mRNA, ligand binding and steroidogenic acute regulatory protein expression during pregnancy. $\mathbf{J}$. Mol. Endocrinol., 1999, 22 : 45-54.

133. TONON M.C., DESY L., NICOLAS P., VAUDRY H., PELLETIER G. : Immunocytochemical localization of the endogenous benzodiazepine ligand octadecaneuropeptide (ODN) in the rat brain. Neuropeptides, $1990,15: 17-24$.

134. TORANZO D., TONG Y., TONON M.C., VAUDRY H., PELLETIER G. : Localization of diazepam-binding inhibitor and peripheral-type benzodiazepine binding sites in the rat ovary. Anat. Embryol., 1994, 979 : 383-388.

135. TRETTER V., EHYA N., FUCHS K., SIEGHART W. : Stoichiometry and assembly of a recombinant $\mathrm{GABA}_{\mathrm{A}}$ receptor subtype. J. Neurosci., 1997, $17:$ 2728-2737.

136. VENTIMIGLIA R., GRIERSON J.P., GALLOMBARDO P., SWEETNAM P.M., TALLMAN J.F., GELLER H.M. : Cultured rat neurons and astrocytes express immunologically related epi- 
topes of the $\mathrm{GABA}_{\mathrm{A}}$ /benzodiazepine receptor. Neurosci. Lett., $1990,115: 131-136$

137. VERMA A., SNYDER S.H. : Peripheral type benzodiazepine receptors. Annu. Rev. Pharmacol. Toxicol., 1989, 29 : 307-322.

138. WALDVOGEL H.J., KUBOTA Y., FRITSCHY J., MÖHLER H., FAULL R.L. : Regional and cellular localisation of $\mathrm{GABA}(\mathrm{A})$ receptor subunits in the human basal ganglia: an autoradiographic and immunohistochemical study. J. Comp. Neurol., 1999, $415:$ 313-340.

139. WANG J.K., TANIGUCHI T., SPECTOR S. : Structural requirements for the binding of benzodiazepines to their peripheraltype sites. Mol. Pharmacol., 1984, 25 : 349-351.

140. WEBB N.R., ROSE T.M., MALIK N., et al. : Bovine and human cDNA sequences encoding a putative benzodiazepine receptor ligand. DNA, 1987, $6: 71-79$.

141. WEIZMAN A., AMIRI Z., KATZ Y., SNYDER S.H., GAVISH M. : Testosterone prevents castration-induced reduction in peripheral receptors in Cowper's gland and adrenal. Brain Res., 1992, $572:$ 72-75.

142. WEST L.A., HORVAT R.D., ROESS D.A., BARISAS B.G., JUENGEL J.L., NISWENDER G.D. : Steroidogenic acute regulatory protein and peripheral-type benzodiazepine receptor associate at the mitochondrial membrane. Endocrinology, 2001, $142: 502-505$.

143. WHALIN M.E., BOUJRAD N., PAPADOPOULOS V., KRUEGER K.E. : Studies on the phosphorylation of the $18 \mathrm{kDa}$ mitochondrial benzodiazepine receptor protein. J. Recept. Res., $1994,14: 217-228$.

144. WOODS M.J., WILLIAMS D.C. : Multiple forms and locations for the peripheral-type benzodiazepine receptor. Biochem. Pharmacol., 1996, 52 : 1805-1814.

145. YAMAGISHI H., KAWAGUSHI M. : Characterization of central- and peripheral-type benzodiazepine receptors in rat salivary glands. Biochem. Pharmacol., 1998, 55 : 209-214.

\section{ABSTRACT}

Endozepines: local testicular steroidogenesis regulation factors

Céline DUPARC, Hervé LEFEBVRE, Marie-Christine TONON, Hubert VAUDRY, Jean Marc KUHN.

Testicular endocrine and exocrine functions are controlled by multiple signals including circulating gonadotropins and locally produced factors. Among these factors, endozepines (EZ), which are the endogenous ligands for benzodiazepine receptors, seem to exert an intracrine, autocrine and/or paracrine stimulatory effect on Leydig cell testosterone production. Benzodiazepine effects are mediated by two types of receptors, i.e. the central-type benzodiazepine receptor (CBR) associated with the GABAA-receptor complex, and the peripheral-type benzodiazepine receptor (PBR) principally located on the mitochondrial membrane and extremely abundant in steroidogenic cells. All EZ characterized to date are derived from an $\mathbf{8 6}$ amino acid polypeptide called diazepam binding inhibitor (DBI) that generates, via proteolytic cleavage, several biologically active peptides including the triakontatetraneuropeptide DBI17-50 (TTN) and the octadecaneuropeptide DBI33-50 (ODN). EZ are widely distributed in the brain and various peripheral organs, particularly in steroidogenic glands. A number of data suggest that, in rats, EZ could regulate testicular steroidogenesis. Firstly, DBI gene expression and the presence of DBI-like peptides have been shown in Sertoli cells, Leydig cells and in late-differentiated germ cells. Moreover, EZ are able to stimulate progesterone and testosterone production by rat Leydig cells and by MA-10 or R2C Leydig tumor cells. Finally, pharmacological studies have shown that EZ stimulate rat testicular steroidogenesis via activation of PBR. PBR appears to be an important component of a dynamic multistep process involving protein-protein interactions, to promote cholesterol translocation in the mitochondria, where it is converted into pregnenolone by cytochrome P450scc.

Key words: endozepines, benzodiazepine receptors, testicular steroidogenesis 